\title{
Iranian ESP Learners' Perceptions of Autonomy in Language Learning
}

\author{
Razieyeh Ahmadi \\ University of Guilan \\ E-mail: raziahmadi22@yahoo.com
}

Received: 23-07- 2012

doi:10.7575/ijalel.v.2n.1p.28
Accepted: 12-09- 2012

Published: 01-01- 2013

\begin{abstract}
Autonomy regarded challenging in EFL contexts, because of the teacher-fronted learning situation, and as literature suggests there is a need for research in areas related to autonomy to measure students' perceptions and evaluate their preparation before the implementation. The purpose of this study is to investigate whether or not, this group of law major students attending English for specific purposes course are ready to be involved in autonomous language learning. For this reason Learner Autonomy Questionnaire designed based on Chan, Humphreys, and Spratt (2002)'s Autonomy Questionnaire and Oxford (1990)'s Strategy Inventory for Language Learning (SILL) and distributed among 133 law major students at the Law Department of University of Guilan. The analysis of results showed that ESP students are not ready for autonomy and they gave most of the important decisions of their learning to their teachers.
\end{abstract}

Keywords: Leaner autonomy, readiness for autonomy, ESP learner autonomy

\section{Introduction}

Autonomy is one of the concepts which originated from learner-centered methodology, and there has been an increasing emphasis on the development of autonomy and autonomous second language learning in different educational settings. The most commonly cited definition proposed by Holec (1981, p. 3) As "the ability to take charge of one's learning" and as "an ability or capacity that needs to acquire" rather than a process". There are principles that are pivotal to the concept of autonomy, one of them is the acceptance of responsibility by the students as Scharle and Szabo (2000) said "success in learning, very much depends on learners having a responsible attitude" (p. 4). This view is consistent with Macaro (1997) 's idea of autonomy. He said the philosophy behind the concept of autonomy considers the human being as a producer in the society rather than a product of it, he also indicated that autonomy is an ability both how to make decisions and "being allowed to make these decisions" (p. 168). Benson (2008) argued autonomy is directly related to learning so the role of the learner and his/her contribution in the process of second language learning is very important. The practice of autonomy in the classroom creates a whole new environment especially in those contexts in which the educational system is teacher-fronted. Another important principle is learning strategies. As Oxford $(2008$, p. 52) stated "learning strategies are signs of autonomy" she also explained "metacognitive strategies are for guiding the learning process itself such as, plan and evaluate" (p. 52). According to Little (1991) learner autonomy is not a "particular method, it is an educational goal that is cross-culturally valid" (p. 21), but the climate of educational setting is influential in the development of autonomous behavior among the students because different cultures have different values and norms that influence the educational practice

For this reason, there has been a long debate among researchers over the applicability of autonomous principles in Eastern educational setting. Littlewood (2000) is one of those researchers who did a lot of research studies to prove that it is just a myth that Asian students are not capable of practicing autonomy in language learning. He conducted a study based on 12-items questionnaire in different Asian countries (India, Burma, China, and Korea) to see whether Asian students' dispositions and preferences are actually based on their obedience to the teacher or not. He compared the responses of Asian students with their European counterparts and concluded that Asian students are actually want to be active and independent, as he stated "they want to explore knowledge themselves" (p. 34) and they do not really want to spoon feed from their teachers.

This research considered this gap in Iran and conducted a study to measure Iranian ESP learners' perceptions towards autonomy in terms of their responsibility perceptions and activity types inside and outside of the classroom, and the employment of metacognitive strategies, because as Littlewood (2000) stated we have to "re-assess" perceptions of our students in different context (p. 34).

\section{Theoretical Background \& Review of Literature}

\subsection{Theoretical Background}

Benson (2006) said "autonomy refers to abilities and attitudes" (p. 2) He said that there is a difference between autonomy and concepts like self-instruction, self-access, self-study, out-of-class learning, and distance learning. The concept of autonomy is viewed differently by different scholars. Dickinson (1995) considered it as an attitude rather than a methodology. Little (1991, p.4) defined autonomy as a "capacity for detachment, critical reflection, decision 
making, and independent action", he considered autonomy as "interdependence rather than independence" (p. 5). Many scholars like (Dickinson, 1994; Littlewood, 1996; Little, 1999) considered it as an educational goal that is applicable in different settings, even in the Eastern educational system. The application of autonomy needs skills and abilities on the part of learners. Dickinson (1994) defined these abilities: They are able to identify the objectives of the classroom; they can create their own goals; they can select the appropriate kind of learning strategies; they can "monitor and evaluate their own use of learning strategies" (p. 7).

Autonomous classroom creates a certain type of role for the teacher, Dam (2008) defined teacher role in an autonomous classroom as a consultant and facilitator. She believed that teacher should involve students in decision making and she/he should give them some information about the demands of the classroom. Little (2004) also argued that teacher should be an observer, advisor, and manager in an autonomous classroom. She/he should create the learning environment, initiates different types of communication in the class and then gives more control to students as soon as she/he feels that they are ready to do things on their own, and finally helps students to move to the next stage.

Little (2004) stated that the lessons and learning materials should be associated with real life and that is what he called the ultimate aim of education to bridge the gap between classroom activities and everyday life needs.

According to Littlewood (1999) there are two types of autonomy: "Proactive and reactive" (p. 75). Proactive autonomy is a type of autonomy which is common in the Western educational system, in which students take the responsibility of choosing objectives, methods, and evaluation. Littlewood (1999) argued, for many, proactive autonomy is the only type of the autonomy. He also proposed another type of autonomy in which all the directions set by the teacher, and learners use all sources "autonomously" (p. 76) to reach the goals. Littlewood (1996) in his theoretical framework, indicated autonomy means two things: "Ability and willingness" (p. 428). He said a person might have the ability to make independent choices but not have the willingness to do so, on the other hand, a person might have the willingness but not capable of making choices. Other components of his framework are motivation, confidence, knowledge, skills. This study is based on Littlewood (1996)'s theory of autonomy and the main principle is learners' responsibility and skills in learning language.

\subsection{The review of Literature}

There is a growing body of research on the development of autonomy and autonomous language learning in EFL context. Autonomous learner should possess a range of abilities and capabilities, according to Benson (2010) "autonomy is a complex construct" (p. 78) he also added "when we judge intuitively that students are either more or less autonomous, what we appear to be doing is observing certain behaviors and associating them with broader construct of autonomy" (p. 78) some of these observable behaviors or variables are strategies, especially metacognitive strategies which show the learners' ability of reflection, planning, and monitoring. Based on the idea of Cotterall (1995) metacognitive strategy is one of the aspects of learners' readiness for autonomy and as Little (1999, p. 23) said "strategic control of language learning and language use" is one of the crucial aspects of autonomy. Oxford (2008) also argued that learners who are more active in the language learning process are those who employed more strategies. As literature suggests before any intervention and fostering autonomy there is a need for research on learners' perceptions towards autonomous language learning.

In one of the early studies Chan (2001) investigated learners' attitudes and expectations of language learning, teacher and learner roles, their learning preferences, perceptions of the learner autonomy, and aims and motivation of language learning. The participants were a group of undergraduate students in Hong Kong Polytechnic University. The results of this study showed that 20 members of this group of students had a positive attitude towards the autonomous approach, but at the same time they preferred their teacher to guide and facilitate autonomy among them. Chan (2001) concluded that the process of developing autonomy among students is a process that should be done slowly and patiently and students must be informed of the benefits of this approach. Chan (2001) revealed two guiding principles for the design of any autonomy-oriented classroom activities:

(a) The teacher should provide opportunities for more students' involvement in the classroom activities.

(b) The teacher should also provide learning conditions in the classroom to stimulate interest and motivation.

In another major study, Chan, Humphreys, and Spratt (2002) investigated the students' readiness for autonomy in language learning. This study examined the students' views towards their responsibilities, and those of their teachers', their confidence in their ability to operate autonomously, and their assessment of their level of motivation to learn English. They employed questionnaire and interview and the results revealed students did not have a good understanding of their own responsibilities and abilities and they considered these more of the teachers' responsibility. The follow up interviews revealed factors that influence their perceived decision-making abilities. Factors like: Necessity or an opportunity to make decisions, prior experience of decision making, the level of confidence, and motivation.

Chan, et al., (2002) suggested two important results:

(a) One way to encourage autonomy is to develop students' motivation to learn. So the development of motivation is a necessary first step.

(b) Teachers can choose the materials and syllabuses that are learner-centered or when they want to choose classroom activities, they need to take these features into account: Learner style, learner preferences, and language learner strategies. 
The only notable study in Iran, conducted by Kashefian-Naini (2002) in which she explored 168 male and female EFL learners' readiness for autonomy in University of Shiraz. She employed Cotterall (1995)'s questionnaire and used factor analysis to show the existence of these factors among this group of Iranian EFL students: (1) learner independence, (2) dependence on teacher, (3) learner confidence, (4) attitudes towards language learning, and (5) self-assessment. She also considered the effect of other variables (age, sex, marital status, grade point average, year of study, their occupation, place of birth, place of residence, and parents' level of education).

Among these variables, only students' academic achievement and professional status of students had an impact on their readiness for autonomy. Students' academic achievement had an effect on learners' autonomy, in that those students with averages 17 to 20 demonstrated a great deal of autonomy. Professional status had an impact on learners' readiness towards autonomy, in that those students with occupation obtained higher indexes of autonomy.

In another study Hashemian and Heidari Soureshjani (2011) investigated the relationship between autonomy, motivation, and academic performance of 60 Persian L2 learners from Sharekord Payam-e-Noor University. They used two questionnaires, one for autonomy developed by Kashefian-Naini (2002) based on Cotterall (1995)'s questionnaire and another one for motivation developed by Vaez (2008). They analyzed the data through correlation and regression. The results showed that there is a significant relationship between motivation and academic performance. This study did not find any relationship between autonomy and motivation.

As Macaro (1997) pointed out "we should always analyze critically theories or principles of second language acquisition that have sprung from studies... carried out in very different institutional learning contexts" (p. 169). He insisted on, we should always check the applicability of these theories in our language learning context. Bhaskaran Nair (2009) argued that autonomy needs to be interpreted in terms of learners' past experiences related to second language classroom and in general to their overall experience.

Autonomy is closely related to learner-centered methodology and as Ellis and Sinclair(1989) claimed it is difficult for learner to adapt to learner-centered methodology, because they have to accept multiple roles such as decision-makers, self-evaluators in which the unfamiliarity and students' lack of preparation may lead to frustration.

Thus, there is a need for research in a local context to measure Iranian students' readiness for autonomy in language learning in terms of their responsibility acceptance and activity types in inside and outside of the classroom, and their employment of metacognitive strategies, because these are the principles which shaped autonomous behavior.

\section{Method}

\subsection{Participants}

The sample of this study was 133 male and female law major students from the Law Department at the University of Guilan, Rasht. They were undergraduate students between the ages of 18 and 25. The sample of the study selected based on purposive sampling. According to Chambliss and Schutt (2003, p. 124) "purposive sample adequately represents the settings or issues of study". The researcher was also used a quantitative research design and employed a questionnaire to answer these questions in an objective manner:

The research questions were: 1. How do ESP students perceive their own and their teachers' responsibilities in learning English? 2. To what extent do these ESP students engaged in inside and outside class activities? 3. To what extent do these ESP students employ metacognitive strategies in learning English?

\subsection{Instrument}

The main instrument of this study was a questionnaire designed by the researcher based on two other questionnaires. Two sections of Chan, et al., (2002)'s Learner Autonomy Questionnaire (responsibility and activity) and part D of Oxford (1990)'s Strategy Inventory for Language Learning (SILL). The autonomous learning activities described in this questionnaire identified by Chan, et al., (2002) as a result of brainstorming sessions with a focus group of students regarding the type of activity that might help them learn language autonomously. The researcher translated the questionnaire from English to Persian language (Farsi) to avoid any ambiguity. The Persian version of it checked and validated by two experts from University of Guilan and then piloted with 35 students who were excluded from final study. The data were analyzed with SPSS version 19.0.

To ensure the reliability of the questionnaire, the researcher ran Alpha Cronbach reliability through SPSS 19.0. The reliability coefficient was found to be .94 which is a high level of reliability.

\subsection{Data Analysis}

In the present study the descriptive statistics (percentages and frequencies) were calculated. The descriptive statistics were also used to find ESP students' engagement in inside and outside autonomous activities. In order to analyze the data related to section three (metacognitive strategies) of the questionnaire, first of all, points ( 1 to 5 ) given by each student to each question were totaled and then divided into the number of items, then the averages rounded off to the nearest hundred. The average point of each student gave the frequency of that students' employment of metacognitive strategies. In order to find out the overall average, the averages of each student were totaled and the result was the metacognitive strategies. Then the result divided into the number of respondents. The results showed the overall employment of metacognitive strategies. This section evaluated based on the key averages suggested by Oxford (1990). The key presented in Table 1 which shows what each average means in terms of students' frequency of strategy use. 
Table 1. Key to the SILL averages

\begin{tabular}{ccc}
\hline High & Always or almost always used & 4.5 to 5.0 \\
& Generally used & 3.5 to 4.4 \\
Medium & Sometimes used & 2.5 to 3.4 \\
& Generally not used & 1.5 to 2.4 \\
Low & Never or almost never used & 1.0 to 1.4 \\
\hline
\end{tabular}

\section{Results and Discussions}

\subsection{Learners' Perceptions of their own and their teachers' responsibility}

In the first section of the questionnaire the participants were instructed to report their perceptions of their own and their teachers' responsibility in the language learning process. Students' perceptions of their responsibility showed their amount of readiness to be autonomous in the language learning process. It is a part of their personal growth and help students to achieve the lifelong learning which is the ultimate goal of education.

Table 2 presents the percentages of responses related to each question, for the ease of interpretation "not at all" and "a little" and "mainly" and "completely" have been combined.

First the researcher calculated the percentages of the responses of each item. The results can be classified into three main categories: (1) students and teachers share the responsibility, (2) teachers have more responsibility than students, and (3) students have more responsibility than their teachers.

For items 1, 3,11, and 12 students shared responsibility with their teachers, these items refer to evaluating their learning, their course, making progress during lessons, and stimulating their interest in learning. For items 2, 4, 5, 9, and 13 students gave the responsibility to themselves, these items refer to checking their progress outside the class, identifying their weaknesses, making work harder, deciding how long to spend on each activity, and deciding what to learn outside the class. For items 6, 7, 8, and 10 students gave the responsibility to their teachers. These items are important and refer to deciding the objectives of the course, deciding what to learn next, and choosing activities and materials to learn English. These are the items that refer to methodological and planning aspects of learning and management of the activities. The findings showed students gave important decisions of their learning process to their teachers, this is the result of traditional educational systems in Iran in which the teacher is the knower and an authority figure in the classroom and students take the order of their teachers, the findings of this study suggested that the type of autonomy expressed in learners' attitude and behavior showed that they were not ready to be involved in autonomous language learning. One of the ways to encourage autonomy is trusting them and giving them respect as an individual in the classroom. The most significant point is that students need to discover in their language learning process.

The participants of this study were law major students and they study English for specific purposes, so they have enough knowledge of their subject matter and they can accept the responsibility of some aspects of language learning. Furthermore needs analysis is one of the ways to make students more involved in selecting objectives. As Richards and Renandya (2002) indicated needs analysis is the starting point for the development of any language learning course. In this way students can involve in the language learning process.

Table 2. Students' Perceptions of their own and their Teachers' Responsibilities--- \% of Respondents

\begin{tabular}{|l|c|c|c|c|c|c|}
\hline \multirow{2}{*}{ Questions } & \multicolumn{2}{|c|}{$\begin{array}{c}\text { Students' perceptions of their } \\
\text { own responsibilities in \% }\end{array}$} & \multicolumn{2}{|c|}{$\begin{array}{c}\text { Students' perceptions of their } \\
\text { teachers' }\end{array}$} \\
\cline { 2 - 7 } & $\begin{array}{c}\text { Not/ A } \\
\text { little }\end{array}$ & Some & $\begin{array}{c}\text { Mainly } \\
\text { Compl. }\end{array}$ & $\begin{array}{c}\text { Not/ } \\
\text { little }\end{array}$ & Some & $\begin{array}{c}\text { Mainly } \\
\text { Compl. }\end{array}$ \\
\hline $\begin{array}{l}\text { 1. Make sure you make progress } \\
\text { During lessons }\end{array}$ & 22.6 & 23.3 & 54.1 & 30.1 & 26.3 & 43.6 \\
\hline $\begin{array}{l}\text { 2. Make sure you make progress } \\
\text { Outside class }\end{array}$ & 25.6 & 13.5 & 60.9 & 54.1 & 21.8 & 24.1 \\
\hline $\begin{array}{l}\text { 3. Stimulate your interest in } \\
\text { Learning English }\end{array}$ & 20.3 & 24.1 & 55.6 & 32.3 & 23.3 & 44.4 \\
\hline $\begin{array}{l}\text { 4. Identify your weaknesses in } \\
\text { English }\end{array}$ & 23.3 & 15.0 & 61.7 & 41.4 & 18.8 & 39.8 \\
\hline 5.Make you work harder & 13.5 & 15.8 & 70.7 & 38.3 & 27.8 & 33.8 \\
\hline $\begin{array}{l}\text { 6. Decide the objectives of } \\
\text { Your English course }\end{array}$ & 38.3 & 21.8 & 39.8 & 24.1 & 21.8 & 54.1 \\
\hline $\begin{array}{l}\text { 7. Decide what you should learn } \\
\text { next in your English lessons }\end{array}$ & 34.6 & 28.6 & 36.8 & 26.3 & 23.3 & 50.4 \\
\hline $\begin{array}{l}\text { 8. Choose what activities to use } \\
\text { to learn English in your English }\end{array}$ & 35.3 & 25.6 & 39.1 & 24.8 & 22.6 & 52.6 \\
\hline
\end{tabular}




\begin{tabular}{|l|c|c|c|c|c|c|}
\hline lessons & & & & & & \\
\hline $\begin{array}{l}\text { 9. Decide how long to spend on } \\
\text { each activity }\end{array}$ & 23.3 & 21.8 & 54.9 & 37.6 & 29.3 & 33.1 \\
\hline $\begin{array}{l}\text { 10. Choose what materials to } \\
\text { use to learn English in your } \\
\text { English Lessons }\end{array}$ & 44.4 & 16.5 & 39.1 & 28.6 & 18.0 & 53.4 \\
\hline 11. Evaluate your learning & 27.1 & 23.3 & 49.6 & 28.6 & 20.3 & 51.1 \\
\hline 12. Evaluate your course & 30.1 & 23.3 & 46.6 & 33.1 & 19.5 & 47.4 \\
\hline $\begin{array}{l}\text { 13. Decide what you learn } \\
\text { outside class }\end{array}$ & 18.8 & 14.3 & 66.9 & 49.6 & 25.6 & 24.8 \\
\hline
\end{tabular}

\subsection{Learners' engagement in autonomous activities}

Section two of the questionnaire shows the frequency of students' engagement in autonomous activities inside and outside of the class. The activities proposed by Chan, et al., (2002) in their study among Hong Kong Polytechnic University students and regarded by them as "possible manifestations of autonomous language learning behavior" (p. 256). The descriptive statistics were employed to show the frequency of ESP students' engagement in inside and outside class activities.

The Table 3 shows the percentages of answers related to each question. Most of the respondents said they "never" do most of the activities, only items 27 (noting down new words and their meanings) and 47 (noting down new information) showed participants "often" engaged in these activities. In items 35 (listening to English songs), 40 (watching English movies), and 50 (discussing learning problems with classmates) respondents said that they "sometimes" engage in these activities.

In terms of inside class activities (items 46, 47, 48, 49, and 50), only for item 47 (noted down new information) respondents said they "often" do this activity.

According to Chan, et al., (2002) this refers to their traditional role as a student in the classroom, they feel their suggestions and comments had no effect on the teachers' decision and once their decision has been made nothing can change it.

In general, these students have never done most of the activities. As Zohrabi (2011) indicated "the status of English language in Iran is an EFL (English as a foreign language)" (p. 125), it is a subject matter in higher education rather than a skill or medium for communication. Students are rarely exposed to English in real life and they said that they are not interested to use internet in English, never practice English with their friends, and never read newspapers and magazines in English. We can conclude that students need more opportunities for learning language inside and outside of the class and lack of facilities and exposure are two important reasons for their disengagement in autonomous activities.

Table 3. The Frequency of Student's Engagement in Outside and Inside class Learning Activities $---\%$ of Respondents

\begin{tabular}{lllll}
\hline Items & Never & Rarely & Sometimes & Often \\
\hline 25. Read grammar books on own & 29.3 & 40.6 & 21.1 & 9.0 \\
26. Done non-compulsory assignments & 36.1 & 30.1 & 21.1 & 12.8 \\
27. Noted down new words/meanings & 11.3 & 25.6 & 29.3 & 33.8 \\
28. Written English letters to pen pals & 60.9 & 22.6 & 13.5 & 3.0 \\
29. Read English notices around you & 53.4 & 30.1 & 15.0 & 1.5 \\
30. Read newspapers in English & 74.4 & 15.0 & 9.0 & 1.5 \\
31. Sent e-mails in English & 59.4 & 22.6 & 15.0 & 3.0 \\
32. Read books/magazines in English & 57.9 & 21.8 & 17.3 & 3.0 \\
33. Watched English TV programs & 24.8 & 34.6 & 22.6 & 18.0 \\
34. Listened to English radio & 58.6 & 18.8 & 17.3 & 5.3 \\
35. Listened to English songs & 23.3 & 24.8 & 26.3 & 25.6 \\
36. Talked to foreigners & 60.2 & 24.1 & 12.0 & 3.8 \\
37. talk to my friends in English & 45.1 & 36.8 & 14.3 & 3.8
\end{tabular}


38. Practiced using English with friends

39. done grammar exercises

40. Watched English movies

41. Written diary in English

42. Used Internet in English

43. Done revision not required by the teacher

44. Collected texts in English

45. Gone to see your teacher about your work
49.6

38.3

21.1

69.9

20.3

30.1

27.1

35.3

44.4

39.1
23.3

30.8

25.6

29.3

14.3

21.8

28.6

6.8

21.1

25.6

20.3

23.3
6.8

6.8

27.1

3.0

18.0

12.0

9.8

8.3

\subsection{Learners' Use of metacognitive strategies}

The last section of the questionnaire focused on ESP learners' employment of metacognitive language learning strategies. According to Thanasoulas (2000) metacognitive language learning strategies are one of the conditions for developing autonomy. This study employed part D of Oxford (1990) Strategy Inventory to find ESP students employment of metacognitive strategies. The averages were computed and evaluated based on Oxford (1990)'s key to averages.

The average score for ESP students' metacognitive strategies use was (3.2). It means that students "sometimes" employ metacognitive strategies in language learning. Metacognitive strategies help students to plan and evaluate their learning. Macaro (1997) divided autonomy into three areas: (1) autonomy of language competence, (2) autonomy of language learning competence, and (3) autonomy of choice and action. In autonomy of language learning competence, he emphasized on the role of metacognitive strategies and said it is one of the abilities that help students to be autonomous in the learning process. So the teacher should help students to develop these strategies and the best way is to train them regarding the use of metacognitive strategies.

In another study, Riazi and Rahimi (2005) found Iranian EFL learners employed a high frequency of metacognitive strategies in language learning, although they were medium strategy users in general. The findings of this study showed there is a need for more studies on the use of metacognitive strategy of Iranian learners in different contexts and among different majors and age groups.

The results showed that students did not not feel ready for the autonomous learning in the most of important aspects of learning and they believed that teaching activity should be designed by the teacher, and teacher has the responsibility of selecting objectives. They did not do most of autonomous activities used in this study and they were medium users of metacognitive strategies. Students need more support and help from their teacher, and they also need training in order to employ metacognitive strategies more frequently in their learning because it is one of the abilities which help students' autonomy in learning. There is one rewarding result in this study and that is the notion of shared responsibility in evaluating. Students had the notion of shared responsibility in evaluating their course and their learning. Little (2011) believed that "one aspect of the individual learner autonomy in language learning is that the learner should have a role in evaluating the learning" (p. 26). The results of this study were in consistent with research study in Hong Kong by Chan, et al., (2002) and showed the educational system and cultural norms and values has an effect on students' readiness for autonomy in language learning.

\section{Suggestions for further research}

This study employed quantitative research design, further study can be designed and employed qualitative research design as well. This study used questionnaire as the main instrument, regarding the instrument, to get a complete picture of students' views, the questionnaire can be accompanied with other instruments such as observation, diary, and interview to achieve more reliable results.

In addition, based on the results of this study course can be designed to promote autonomy among students.

Finally, further study needs to be conducted and considered other related issues of autonomy such as learners' role, teachers' role, and students' locus of control.

\section{Acknowledgement}

Hereby, I would like to express my sincere gratitude to my Professors Dr. Mahdavi and Dr. Barekat for their continuous support, advice, and immense knowledge.

\section{References}

Benson, p. (2006). Learner autonomy: Insider perspectives on autonomy in language teaching and learning. Dublin: Authentik.

Benson, P. (2008). Teachers' and learners' perspectives on autonomy. In T. Lamb \& H. Reinders (Eds.), Learner and 
teacher autonomy: Concepts, realities, and responses. Amsterdam: John Benjamins.

Benson, P. (2010). Measuring autonomy: Should we put our ability to test? In A. Param \& L. Siercu (Eds.), Testing the untestable in language education (pp. 77-91). Bristol: Multilingual Matters.

Bhaskaran Nair, P. (2009). Redefining learner autonomy in the Indian ESL context. In Y. L. Patel \& M. A. Vyas (Eds.), Teaching English as a second language: A new pedagogy for a new century (pp. 212-217). New Delhi: Jay Print Pack Limited.

Chambliss, D., \& Schutt, R. K. (2003). Making sense of the social world: Methods of investigation. Thousands Oaks, Calif: Pine Forge Press.

Chan, V. (2001). Readiness for learner autonomy: What do our learners tell us? Teaching in Higher Education, 6 (4), 505-518.

Chan, V., Humphreys, G., \& Spratt, V. (2002). Autonomy and motivation: Which comes first? Language Teaching Research, 6 (3), 245-266.

Cotterall, S. (1995). Developing a course strategy for learner autonomy. ELT Journal, 49 (3), 219-227.

Dam, L. (2008). How do we recognize an autonomous classroom?--- Revisited. In P. Benson, L. Dam L. Legenhausen \& R. Manchon (Eds.), Spain, Proceedings of TESOL symposium. Learner autonomy: What does the future hold? (pp. 13-27). Sevilla, Faculty of Languages: University of Sevilla, Spain.

Dickinson, L. (1994). Learner autonomy: What, why, and how? In V. J. Leffa (Ed), Autonomy in language learning (pp 2-12). Porto Alegre: Universidade/UFRGS.

Dickinson, L. (1995). Autonomy and motivation: A literature review. System, 23 (2), 165-174.

Ellis, G., \& Sinclair, B. (1989). Learning to learn language. Cambridge: Cambridge University Press.

Hashemian, M., \& Heidari Soureshjani, K. (2011). The interrelationship of autonomy, motivation, and academic performance of Persian L2 learners in distance education contexts. Theory and Practice in Language Studies, 1 (4), 319-326.

Holec, H. (1981). Autonomy in foreign language learning. Oxford: Program Press.

Kashefian-Naini, S. (2002). An investigation into college EFL learners' beliefs demonstrating their predispositions towards learner autonomy. Unpublished masteral thesis, Shiraz University, Shiraz, Iran.

Little, D. (1991). Learner autonomy: Definitions, issues, and problems. Dublin: Authentik.

Little, D. (1999). The European language portfolio and self-assessment. Strasburg: Council of Europe Retrieved, June, 2011

from

http://archive.ecml.at/mtp2/Elptt/Results/DMlayout/Reference\%20Materials/English/David\%20Little\%20selfassessment $\% 20$ E.pdf.

Little, D. (2004). Constructing a theory of learner autonomy: Some steps along the way. In K. Makinen P. Kaikkonen \& V. Kohonen (Eds.), Future perspectives in foreign language education (pp. 15-25). Oulu, Finland: Publications of the Faculty of Education.

Little, D. (2011). The common European framework of reference for languages: A research agenda. Language Teaching, 44 (3), 381-393.

Littlewood, W. (1996). Autonomy: An anatomy and a framework. System, 24 (4), 427-435.

Littlewood, W. (1999). Defining and developing autonomy in East Asian contexts. Applied Linguistics, 20 (1), $71-94$.

Littlewood, W. (2000). Do Asian students really want to listen and obey? ELT Journal, 54(1), 31-35.

Macaro, E. (1997). Target language, collaborative learning and autonomy: Modern languages in practice. Clevedon, Philadelphia, USA: Multilingual Matters.

Oxford, R. L. (1990). Language learning strategies: What every teacher should know. Boston: Heinle \& Heinle.

Oxford, R. L. (2008). Hero with a thousand faces: Learner autonomy, learning strategies, and learning tactics in independent language learning. In S. Hurd \& T. Lewis (Eds.), Language learning strategies in independent settings (pp. 41-67). Toronto: Multilingual Matters.

Riazi, A., \& Rahimi, M. (2005). Iranian EFL learners' patterns of language learning strategy use. Journal of Asia TEFL, 2 (1), 103-129.

Scharle, A., \& Szabo, A. (2000). Learner autonomy: A guide to developing learner responsibility. Cambridge: Cambridge University Press.

Thanasoulas, D. (2000). What is learner autonomy and how can it be fostered? Internet TESL Journal, 6, 1-11.

Zohrabi, M. (2011). Enhancing learner autonomy through reciprocal approach to curriculum development. English Language Teaching, 4 (3), 120-127. 